\title{
The Application Design of Smart Home Model System Using Solar Energy Based on Embedded System
}

\author{
Yu Xiaohai \\ City Institute of Dalian University of Technology \\ Dalian, China
}

\author{
Jin Jianshe \\ City Institute of Dalian University of Technology \\ Dalian, China
}

\begin{abstract}
According to the application design of smart home model system using solar energy based on embedded system, the paper elaborated total structure, design project and main characteristics of smart home system. Simultaneously, the paper emphasized the importance of using solar energy for smart home system. Through the paper, authors hope that more clean energy can come into people's life. So we can contribute our strength to the healthy development of green Earth.
\end{abstract}

Keywords-Solar energy, Photovoltaic system, Smart home model, Embeded System

\section{INTRODUCTION}

As we all known, along with the rapid development of social economy, the mankind's need to the energy increases greatly. Therefore, much annoyance for our green Earth increases invisibly. How to protect our Earth? How to improve the living environment of people? How to use more clean energy to satisfy people's daily life need? Be exactly owing to the thinking of these problems, this paper studied solar energy's application in the modern smart home system and tried to find out some design methods and principle, which can apply solar energy to people's daily life.

\section{TOTAL STRUCTURE OF THE SYSTEM}

Smart home model system using solar energy based embeded system, such as figure 1 show. From the diagram, the whole system mainly includes the PV system of solar energy, auto-control module of SCM, smart home model and the AS-UII robot development platform for controlling the smart home model.

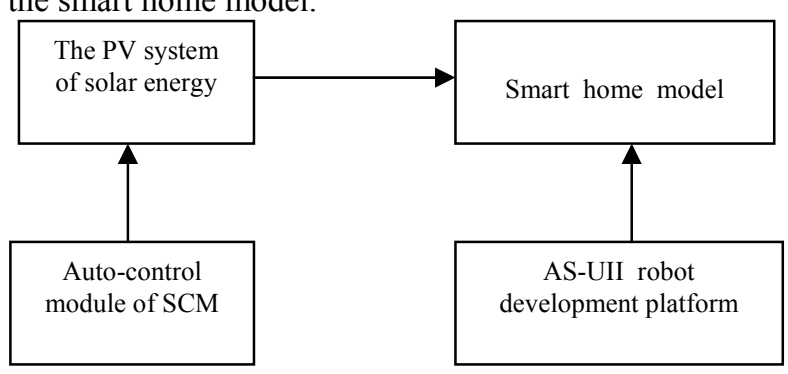

Figure 1. The composition of smart home model system using solar energy

Among them, the PV system of solar energy consists of the solar array-battery board, storage battery and DC-to-AC converter. The main function of the PV module is that to change solar energy to electric power for appliances' power supply of the smart home model. The auto-control module of SCM consists of AT89C51 chip, ADC0809 chip and other driving circuit. This SCM module carry out automatic charging or discharging to the storage battery. Then we can protect the use of storage battery. The smart home model based AS-UII robot development platform, is mainly used for imitating the living home environment of the mankind. Among them, the AS-UII robot development platform provides some structure parts for constructing smart home model, and also provides many kinds of sensors and DC motors. For example, it provides light sensors, magnetism sensors, temperature sensors and infrared sensors...etc. Through these spare parts, we built following control object in the smart home model. For example, the intelligence door for guarding against theft, a dynamoelectric pulling window, a kitchen for putting out smoke automatically, a skylight based the temperature sensor, a garden on the room top, an indoor elevator and indoor temperature control facilities etc. For these intelligence control objects in the smart home model, we can program software through AS-UII robot development platform to control the sensors and DC motors at real time. Then we can imitate the living scene of people. Such as figure 2 show, is the real object diagram of smart home model using solar energy.

\section{THE DETAILED DESIGN PROJECT}

\section{A. The PV system of solar enery}

The PV system of solar enery can directly convert solar radiation energy into electric power [1]. It mainly consist of solar array-battery board, controller, storage battery and DC-to-AC converter, such as figure 3 show.

Among them, the solar array-battery board can change solar energy to electric energy. It is a spare part of converting energy. Storage battery, its function is to store solar energy and send out electric power. Usually the output is a direct current power. In this system, the rated voltage of storage battery is $12 \mathrm{VDC}$. DC-to-AC converter is the equipment that converts direct current into alternate current power. The output of storage battery is direct current power. While a lot of equipments are alternate current appliances, therefore DC-to-AC converter need to be used. Controller, carry out the automatic charging or discharging to the storage battery. In this system, we use SCM as a controller. B. The Auto-control module of SCM 
This module mainly includes an AT89C51 chip, an ADC0809 chip and other driving circuit. The principle of the whole SCM system, such as figure 4 show.

From the diagram, AT89C51 controls ADC0809 chip which can finish $\mathrm{A} / \mathrm{D}$ conversion, to collect the output voltage of storage battery in fixed time. When the output voltage is smaller than 9VDC, the SCM controls driving circuit to start charging for the storage battery. When the output voltage is bigger than 13VDC, the SCM module controls driving circuit to start discharging for the storage battery. Meanwhile the module controls to turn on the circuit of related electric equipments [2]. For a moment, AT89C51 will again examine the voltage of storage battery. When the output voltage is smaller than $12.5 \mathrm{VDC}$, the SCM module controls driving circuit to stop discharging for the storage battery. At this moment, the storage battery starts to give each kind of electric equipments power supply. After a period of time, AT89C51 will collect the voltage of storage battery. When the output voltage of storage battery is smaller than $11 \mathrm{VDC}$, the storage battery will be restarted to charge until the output voltage is bigger than 12VDC. Through the above process, when we make the output voltage be a reasonable rage, we will prolong the service life of storage battery.

C. The design of smart home model

In the system, we mainly built the following control object. For example, the intelligence door for guarding against theft, a dynamoelectric pulling window, a kitchen for putting out smoke automatically, a skylight based the temperature sensor, a garden on the room top, an indoor elevator and indoor temperature control facilities etc. Here mainly introduces the intelligence door for guarding against theft, the skylight based the temperature sensor and indoor temperature control facilities.

\section{1) The intelligence door for guarding against theft}

The smart home adopted the password lock to the door for guarding against theft. You can set the initial password and unlock code to the lock according to personal requirement. When the password is inputted wrongly, the door will be locked. Then you must firstly input the unlock code correctly, or you will not be permitted to input the password. When the host leaves home with pressing a key named locking door, then the door will be locked automatically. After locking the door, the system will run the program of guarding against theft. At this time, if someone collides door or windows strongly, through the touching sensors, the system will automatically send out a police sound and light to awoke the policemen and the guards. The intelligence guards against theft door and a dynamoelectric pulling window, such as figure 5 show

\section{2) The skylight based the temperature sensor}

The skylight based the temperature sensor is established on the building crest of smart home model. The way of opening or closing the skylight, is automatic or manual. When the outside air temperature which can be collected by temperature sensors is suitable for people, the skylight will be open and the fresh air will come into the home. Otherwise, the skylight will be closed. Sometimes, if you want to open or close the skylight by manual way, then you can firstly stop auto-control system through temperature sensors, and secondly use your hands to open or close the skylight. The real object model design of the skylight, such as figure 6 show. At left-hand in the diagram is the skylight model, the right side of the skylight is the building crest garden and an indoor elevator object model

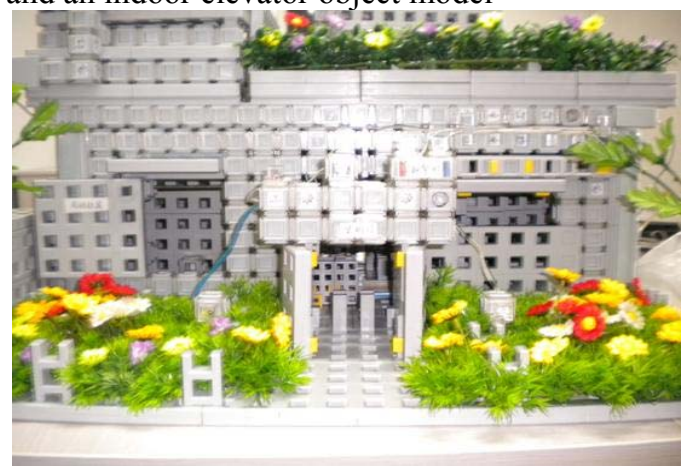

Figure 5. The intelligence door and a dynamoelectric pulling window

\section{3)The indoor temperature control facilities}

The inner part of smart home model also has the indoor temperature control facilities, which consist of subterranean heat devices and water-circling devices. Among them, the subterranean heat devices mainly used for heating cold water by delivering the solar energy of surplus to the waterheater in winter. At the same time, we should open the switch of subterranean heat water-circling, and make the hot water circulate fluxion, and then raise indoor's air temperature. The object model of the subterranean heat facilities, such as figure 7(left side) show. However summer comes, we need to make the air temperature be low. At this moment, the water-circling devices are placed into work status. we can open the switch of external water-circling, and close the switch of subterranean heat water-circling. At this time, the solar energy of the surplus is used to providing power supply for turbine electric motor, which can make the outside lower temperature water lead into indoor continuously. Then the cold water can make the air temperature of indoor be low gradually. The real object model of water-circling facilities, such as figure 7(right side) show.

\section{MAIN CHARACTERISTICS OF THE SYSTEM DESIGN}

Firstly, this system adopted PV system of solar energy to output power for the electric equipments' power supply. The low carbon is free from pollution. This paper show that we can convert the infinite solar energy as electric power for people's daily life. Secondly, the system adopted to economy energy design. For example, we designed a garden on the room top, beautified environment, and also made indoor warm in winter and cool in summer. This design can reduce the use of electric appliances like air-condition. For another example, we adopted water-circling system in the home. The water-circling system can be used for the subterranean heat appliances to warm the air in winter. 
Thirdly, the system has intelligence to make people's life be more comfortable. For example, in the home there is an elevator. The host can conveniently go to the garden on the room top during his spare time. For another example, the kitchen adopted infrared sensors based flame. When the sensors detected the flame, the smoke would be put out immediately.

\section{SUMMARIES AND PROSPECTS}

To summarize, the energy problem is a huge challenge that is the whole human being to face. The Earth already has been very tired, and her burden is too heavy. Who can rescue our Earth? Who can rescue our future? The answer is Only ourselves. Only we by ourselves with the progress and development of science technique unremittingly, improve the using mode of energy in our home living environment continuously, perfect and creative the application and expansion of clean energy continuously, then we can make the whole Earth more healthy growth, and then we can make tomorrow of mankind become more better.

\section{REFERENCES}

[1] Zhang Jin-hua.Compute Analysis of the Capacity of PV System of Solar Energy. Gansu Science and Technology[J], 2009.6, PP: 57-60

[2] Jin Jian-she.The Principle and Application of SCM[M]. Peking: BeiJing University of Posts and Telecommunications Press, 2009, PP: 281-283

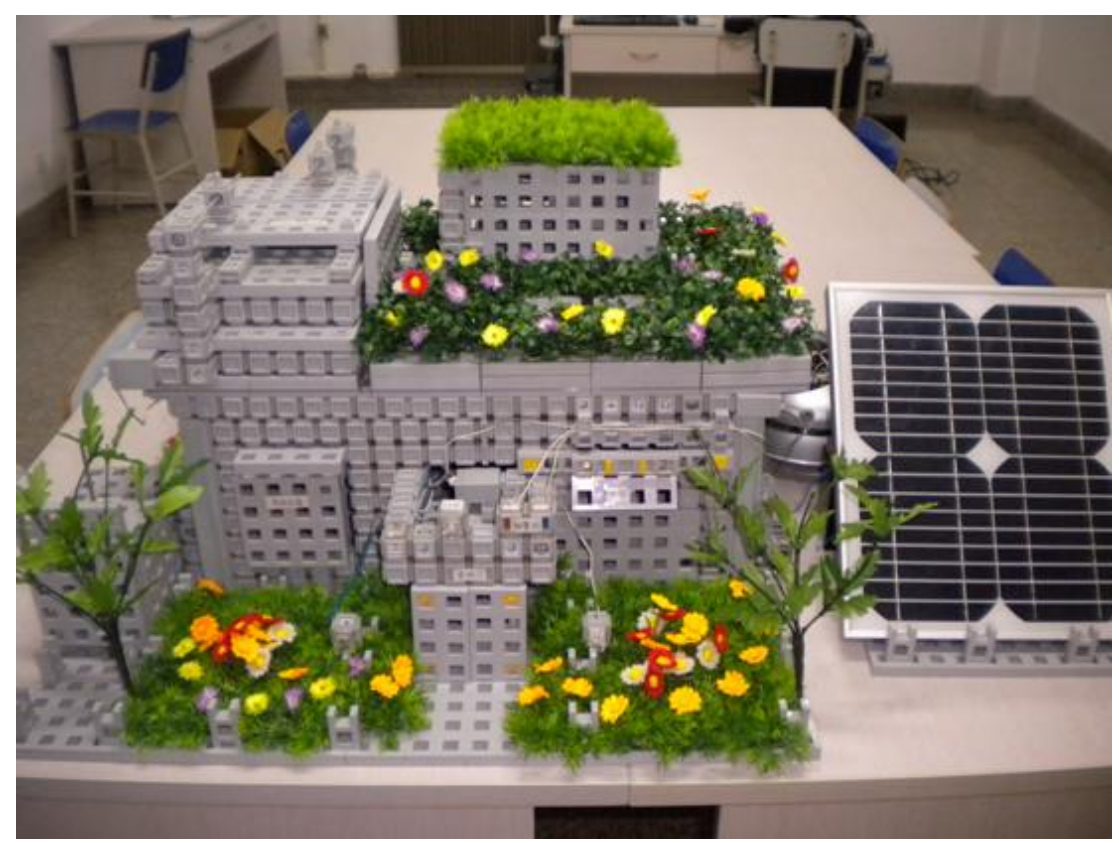

Figure 2. The real object diagram of smart home model using solar energy

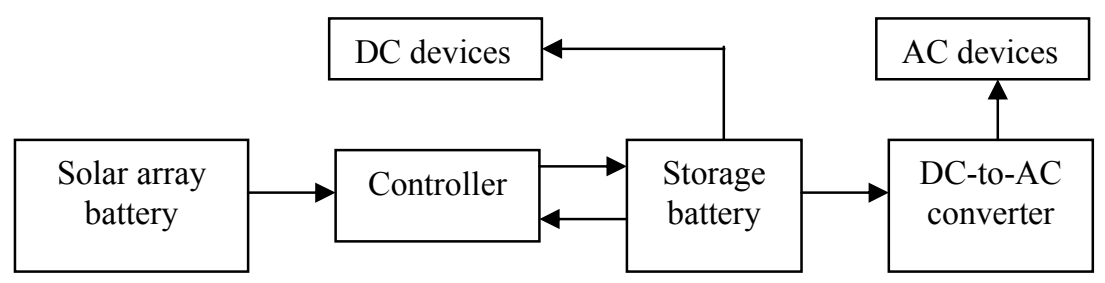

Figure 3. The PV system of solar energy 


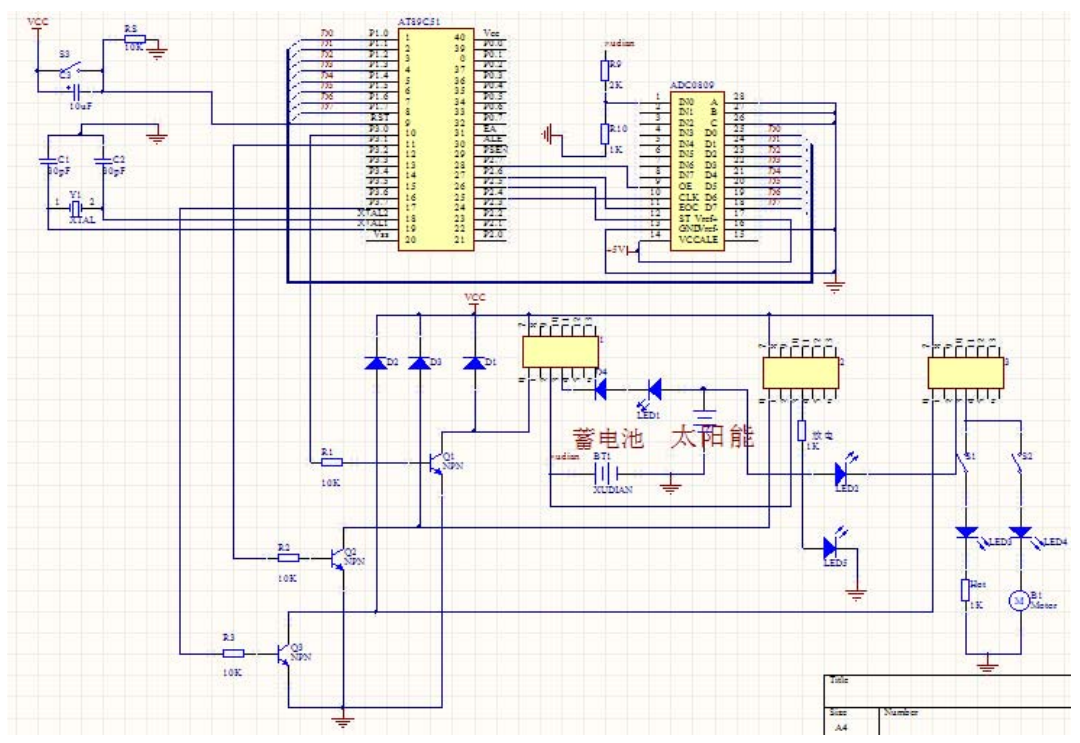

Figure 4. The principle of the whole SCM system

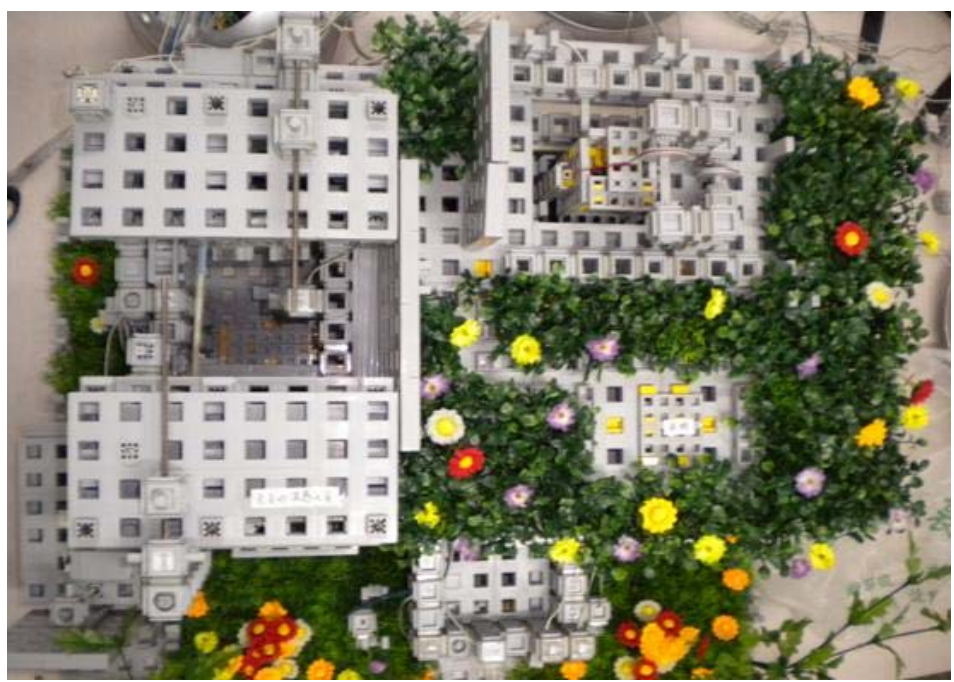

Figure 6. The skylight, the building crest garden and an indoor elevator model
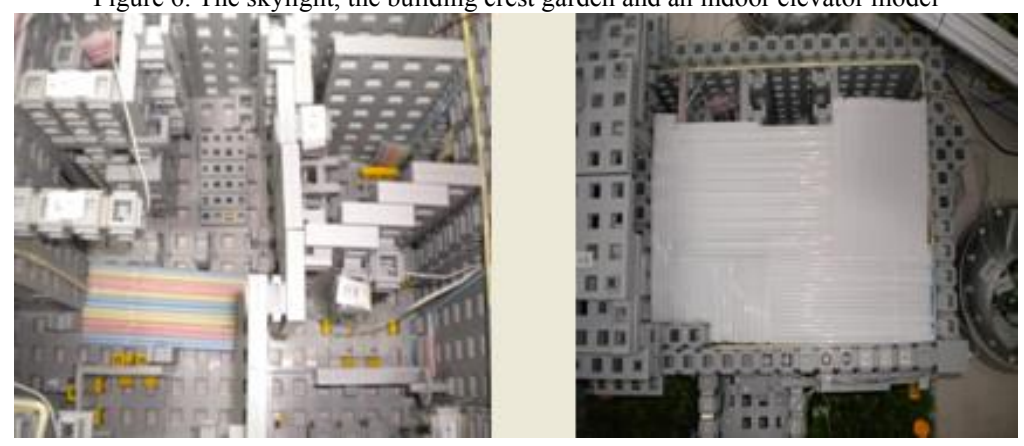

Figure 7. The model of subterranean heat and water-circling facilities 